LA W RENCE LIVERMORE N A T IO N A L LABORATORY
Simulation of plasma fluxes to material surfaces with self-consistent edge turbulence and transport for tokamaks

T.D. Rognlien, M.V. Umansky, X.Q. Xu, R.H. Cohen, L.L. LoDestro

December 12, 2003

16th Plasma Surface Interation Conference Portland, ME, United States May 24, 2004 through May 28, 2004 
This document was prepared as an account of work sponsored by an agency of the United States Government. Neither the United States Government nor the University of California nor any of their employees, makes any warranty, express or implied, or assumes any legal liability or responsibility for the accuracy, completeness, or usefulness of any information, apparatus, product, or process disclosed, or represents that its use would not infringe privately owned rights. Reference herein to any specific commercial product, process, or service by trade name, trademark, manufacturer, or otherwise, does not necessarily constitute or imply its endorsement, recommendation, or favoring by the United States Government or the University of California. The views and opinions of authors expressed herein do not necessarily state or reflect those of the United States Government or the University of California, and shall not be used for advertising or product endorsement purposes. 


\title{
Simulation of plasma fluxes to material surfaces with self-consistent edge turbulence and transport for tokamaks"
}

\author{
T.D. Rognlien, M.V. Umansky, X.Q. Xu, R.H. Cohen, and L.L. LoDestro \\ Lawrence Livermore National Laboratory, University of California, \\ Livermore, CA 94550 USA
}

The distribution of plasma fluxes to material surfaces is a key issue for fusion devices because it controls peak heat loads and determines hydrogenic and impurity particle sources via recycling and sputtering. The typical modeling approach for tokamaks has been to simulate the scrape-off layer (SOL) plasma with 2D transport codes that assume enhanced turbulence-induced transport across the magnetic field to fit experimental profiles. Plasma turbulence simulations for fixed profiles [e.g., Ref. 1] show that turbulent fluxes of the required magnitude arise from instabilities driven by the radial plasma gradients. However, because the profiles and turbulence are strongly coupled, being able to predict the plasma fluxes in future devices such as ITER requires coupling of simulations for turbulence and profile evolution. The approach reported here is coupling the BOUT 3D turbulence code [1] with the UEDGE 2D transport code [2]. Initial coupling of only the hydrogen density variable for fixed temperature profiles is presented in Ref. 3. Here the coupling is extended to the electron and ion temperatures and the parallel velocity. Neutrals are treated self-consistently via a full flux-limited fluid model. Because the characteristic time scales of the turbulence is short $\left(\sim 10^{-6} \mathrm{sec}\right)$ and the profile evolution time scale can be long $\left(\sim 10^{-2}-10^{-1} \mathrm{sec}\right.$ owing to recycling), an iterative scheme [4] is used that relaxes the turbulent fluxes passed from BOUT to UEDGE and the profiles from UEDGE to BOUT over many coupling steps. Each code is run on its own characteristic time scale, yielding a statistically averaged steady state. Since the turbulent fluxes are coupled directly to UEDGE with no assumption of small-amplitude diffusive transport, and the effect of strong, intermittent transport events are included. Results show that strong convective transport can arise in the far SOL for L-mode-like discharges, giving significant wall recycling. Comparisons are made between particle and energy fluxes to the main chamber walls and to the divertor plates for different conditions. The model is unique in its self-consistent treatment of turbulence and transport on both sides of the magnetic separatrix; thus, the model simulates the generation of the turbulence, its propagation to the wall, the resulting neutral influx, and profile modifications.

"Work was performed under the auspices of US DOE by University of California Lawrence Livermore National Laboratory under contract No. W-7405-ENG-48 and was supported by LLNL LDRD project 03-ERD-009.

[1] X.Q. Xu, R.H. Cohen, T.D. Rognlien, and J.R. Myra, Phys. Plasmas 7 (2000) 1951.

[2] T.D. Rognlien, D.D. Ryutov, N. Mattor and G.D. Porter, Phys. Plasmas 6 (1999) 1851.

[3] T.D. Rognlien, M.V. Umansky, X.Q. Xu, R.H. Cohen, to be pub., Contrib. Plasma Phys.

[4] A.I. Shestakov, R.H. Cohen, J.A. Crotinger, L.L. LoDestro, A. Tarditi, and X.Q. Xu, J. Comp. Phys. 185

(2003) 399. 